\title{
Teaching Self-Regulation Skills to Improve Academic Achievement
}

\author{
Marlys T. Vaughn \\ Millsaps College, USA
}

\begin{abstract}
The link between students' abilities to selfregulate socially and emotionally is strongly related to students' academic achievement. Students' abilities to self-regulate directly impact classroom climate and thus classroom management. Classroom management is becoming more challenging, but most teacher preparation programs are not training pre-service teachers to teach students self-regulation skills.

Policy makers, educators, and the public agree that schools should prepare students to be proficient not only in academic content areas but also in abilities to cooperate and engage others from diverse backgrounds in socially and emotionally appropriate ways. Developmental research reports effective mastery of social and emotional competencies directly relate to greater well-being and higher academic performance. Teacher preparation programs must prepare pre-service teachers to teach students self-regulation skills.
\end{abstract}

\section{Introduction}

A major challenge for $21^{\text {st }}$ century schools involves serving diverse students from various experiential backgrounds and various abilities and motivations for learning. Educators are finding many students lack the social-emotional skills and dispositions for successful learning and participation in educational and social settings. Such students tend to become less successful in school as they progress from elementary school to middle and high school and such lack of success directly impacts students' academic performance and behavior [2].

General agreement exists among policy makers, educators and the public that schools should prepare students to be proficient not only in academic content areas but to also prepare students to able to cooperate and engage those from diverse backgrounds in socially and emotionally appropriate ways and to interact responsibly and respectfully with others. The educational system, in its most effective means, must not only enhance cognitive development but also the emotional and social development of students. However, schools certainly have limited resources and are undergoing intense scrutiny and pressure to enhance students' academic performance.

The direct link between students' social and emotional learning (SEL) and students' academic success in schools and in life in general is not a new precept [14]. Much developmental research reports that effective mastery of self-regulation in social and emotional competencies directly relates to greater well-being and higher academic performance; the failure to achieve competence in social and emotional skills and dispositions often results in a host of academic, social, and personal problems. On the other hand, some question the degree to which promoting students' social and emotional skills actually translates to improved academic achievement.

\section{Literature Review}

A strong link exists between students' abilities to engage in self-regulation, a vital component in SEL, and their academic achievement. Ellen Galinsky, co-founder of the Families and Work Institute and author of Mind in the Making, states that controlling and regulating one's thinking, emotions, and resulting behaviors, are essential for success in academic and life-long endeavors [7]. Research clearly finds that young children engaging in direct, intentional self-regulation behaviors learn more and pursue higher educational achievements [3]. Teacher preparation programs must better prepare future teachers to both understand and practice self-regulation abilities as well to be able to teach self-regulation skills to students.

After conducting an informal electronic survey the author found $76 \%$ of licensure graduates from the institution felt inadequate in teaching selfregulation skills and dispositions in their classes. As classroom management remains a primary concern in today's classrooms, better understanding of and instruction in self-regulation behaviors could have a 
positive impact on both classroom management and academic performance resulting in a win-win situation for both students and teachers. Niesyn [12] reports that due to mandates from No Child Left Behind Act of 2001 (in the United States) requiring teachers to be "highly qualified", by having subject area expertise in content areas in which teachers are the primary instructor, teachers' feelings of inadequate preparation to teach selfregulation skills are very likely to persist. Current classroom emphasis is on content knowledge rather than pedagogy. In addition, Kessler [11] claims that teachers need a better pedagogical model to meet both the academic and social-emotional needs of today's students.

Self-regulation can be defined as developing the ability at an early age to form close and secure peer and adult relationships, to regulate and express emotions in developmentally appropriate ways, and to learn from one's environment [14]. Important for self-regulation are the abilities to be aware of and manage emotions, to set and work toward positive goals, to maintain positive relationships, to make responsible decisions, and manage interpersonal experiences in an appropriate and positive manner. Related competencies include self-management abilities which should promote better adjustment and academic progress, including fewer conduct problems and less emotional distress and improved academic performance in grades and tests scores [12].

Self-regulation includes various complicated processes that allow students to respond appropriately to environmental experiences. Students must develop the ability to self-regulate in order to communicate, to select appropriate responses to environmental factors, and to act on responses in a responsible manner. Blair \& Diamond [2] describe self-regulation as an interaction among several domains, and regulation of one domain affects other domains. Emotional and cognitive self-regulation interact and are not separate abilities or skills. Emotions affect thinking and thoughts affect emotions. Students who are highly anxious tend to avoid challenging learning processes; when students learn to regulate difficult emotions they are better able to focus on academic endeavors. Such regulation of anxiety and other uncomfortable feelings provides opportunity for students to develop tenacity to complete challenging tasks and increases the likelihood of practicing skills for mastery. Students' behaviors are affected by many external environmental and other factors, however, researchers conclude students' intentional self-regulation is highly predictive of academic success [12].

Self-regulation skills develop gradually and improve with systematic, intentional modeling and prompting to progress toward the ideal of internalized self-regulation. As teachers provide many opportunities for students to observe, experience, and practice self-regulation skills such as impulsivity control, management of anger and frustration, ability to routinely share and cooperate with others, and directing and focusing attention to learning activities, students develop the ability to self-regulate independently and internalize such skills and behaviors. Teaching self-regulation skills to young children requires bridging and scaffolding opportunities for students to observe and practice such skills to progress toward the ultimate goal of internalized self-regulation.

Modeling, providing hints and cues, and providing direct teacher support and encouragement are effective pedagogical techniques for promoting self-regulation with young students. Teachers intentionally model appropriate self-regulation behaviors as students observe; teachers model correct ways of holding books, how to share instructional materials, ways to take turns in conversation, and methods of "cooling" anger and frustration.

Sitting in a whole group on a rug for reading instruction can be difficult for students not having internalized self-regulation. Teachers model ways of sitting with legs crossed and hands beneath legs to reduced students' contact with others; contact such as touching other students' clothing or nudging other students is distracting and leads to behavior interruptions. Next, teachers may model sitting on the rug with one's hands in one's lap as teachers scaffold to more appropriate ways of sitting and not disturbing others nearby. Such modeling by teachers provides systematic, frequent, and intentional examples for students to observe and practice self-regulation.

Important cues such as gestures, hand signals, and physical proximity direct students to ways for self-regulating their attention and behaviors. A teacher's raised hand can be a signal for students to stop talking and focus attention on the task at hand. Pointing to a particular center in the classroom provides hints directing students to learning activities and on-task behaviors. Cuing students about ways to control impulsivity and anger are important practices with students lacking internalized self-regulation; cuing students to put their hands in their pockets or to hold their hands can provide students with alternatives to impulsive grabbing and hitting while helping students practice self-regulation habits.

Through direct teacher support and encouragement, teachers focus instructional techniques on the development of self-regulation skills in young students by rehearsal strategies such as highlighting and underlining key words and discussing picture cues in texts. Such rehearsal strategies are teacher directed and usually occur as a 
part of whole-class or small group instruction. To direct students' skills in attending and focusing, after reading aloud a short story, for example, teachers assess and reinforce comprehension through questions regarding main ideas, sequencing of events, and supporting details in text. Such teacher directed instructional procedures not only lead to deeper processing of text, but also provide young students with practice in self-regulating their learning and comprehension. Self-regulation skills developed through direct, explicit instruction in attending and focusing encourage young students to persist in the assigned task, to think aloud with others and share ideas with others, to learn and implement ideas and suggestions from peers, and to practice questioning the next appropriate steps to take to complete the task.

In assisting students in the development of selfregulation skills, teachers shape instruction and the classroom environment so that students feel a sense of empowerment through opportunities for decision making, for selection of learning activities, and for showcasing their accomplishments. Such efforts promote students' views regarding their abilities to successfully complete assignments and other academic expectations, resulting in a greater sense of self-efficacy. Central to development of selfefficacy, individuals' regard for their abilities to accomplish instructional goals and assignments, is the opinion that the instructional tasks and expectations are important, relevant, and interesting. Direct teacher instruction, including oral explanations, reasons why the material is important, and ways the content can be used in the future, provide the framework for the importance and value of learning and the importance for students' selfregulation development. As teachers model, provide hints and clues, and directly provide support and encouragement in all classroom endeavors, teachers guide students toward developing self-regulation skills such as focusing, attending to tasks at hand, controlling and managing anger and impulsivity.

As teachers incorporate direct, systematic instruction while teaching students self-regulation skills, teachers observe individual student's behavior patterns and progress in student's regulation of emotions and behaviors. Such careful observations will direct teachers' timing in slowly withdrawing direct self-regulation support through modeling and cuing students as students' self-regulation skills gradually become more internalized [6].

\section{Research Rationale}

Social-emotional competence has a significant correlation to academic achievement; Bernard found developmentally appropriate self-regulation abilities to be a strong predictor of five-year-old children's reading achievement levels and those children "at risk" for academic problems showed much lower abilities to self-regulate [1]. Further, more recent research suggests that instruction in self-regulation may have an effect on the central executive cognitive functions in the prefrontal areas of the brain's cortex, likely resulting in greater socialemotional self-regulation [9].

The Illinois State Board of Education "incorporated SEL skills as part of their student learning standards, identifying three broad learning goals: (a) develop self-awareness and selfmanagement skills to achieve school and life success, (b) use social awareness and interpersonal skills to establish and maintain positive relationships, and (c) demonstrate decision-making skills and responsible behaviors in personal, school, and community contexts" [5]. These learning goals must be taught and many students enter schools with a much narrower range of appropriate social and emotional responses than teachers expect. Responses such as empathy, compassion, cooperation, patience, and sympathy are not innate emotions and must be learned. Many teachers assume such social-emotional development, particularly self-regulation, is taught and modeled in students' homes and therefore students are equipped with appropriate responses when they enter schools. This assumption is false and such skills must be taught and demonstrated in today's classrooms. In addition, self-discipline and self-regulation are more closely correlated to academic achievement than students' intelligence quotient scores. [10]. With the emphasis on content mastery and high stakes tests performance, teachers are not trained and prepared to teach social-emotional skills, particularly the selfregulation skills for impulse control, anger management, cooperation, and collaborative problem solving.

\section{Analysis of Findings}

An initiative to develop a field-based course to teach both pre-service teachers and current teachers the content and pedagogy for providing instruction in self-regulation skills is supported by a modest grant. The grant provides support for two course releases to develop the new course and to provide stipends for elementary teachers participating in the initiative. The goals of the initiative include providing direct instruction in self-regulation with young children, building capacity to improve classroom management within the teaching profession, and establishing a viable, sustainable model for developing children's self-regulation and pro-social skills which can be used to pilot similar programs at other schools.

Studies of best practices for teaching selfregulation are generally consistent in finding that self-regulation can be taught with explicit instruction, by modeling, providing hints and cues, 
scaffolding activities designed to internalize selfregulation behaviors, and designing and leading discussions for reflection on behaviors and appropriate responses for personal growth. Instructional time invested in teaching selfregulation benefits all students, not just those with behavioral problems. Some strategies include teaching students to monitor their own behaviors, to evaluate their behaviors, to set behavioral goals, and to reflect on goals and outcomes [12]. More successful programs are interactive, employ role playing, modeling, and coaching, and include structured activities, often collaborative, to achieve specific goals and solve problems, and foster reflection on goals and behaviors [4].

The initiative, a partnership between a small liberal arts college's Department of Education and the local school district, has resulted in the development of a new course for pre-service teachers and teachers at a local school piloting the program. Pre-service teachers and current teachers learn ways of instructing elementary students to enhance students' self-regulation skills. The director if the initiative teaches both current teachers in the local pilot school along with pre-service teachers at the school site in afternoon classes. Pre-service teachers, along with teachers in the pilot school, will implement these skills in elementary classrooms. Building on the department's distinctive strengths, the new course will be heavily field based while preservice teachers and teachers together study relevant research, theories, and techniques for implementing the program. Pre-service teachers, under supervision of the course instructor, work directly with children at the host school. The course will be taught on the school site beginning in fall, 2013, and continuing each academic semester.

Once pre-service teachers have completed the introductory-level new course, they may enroll in a second, internship-level course, in which they take greater responsibility in teaching self-regulation skills to young children using research based best practices from the introductory new course. The second internship-level course provides pre-service teachers and teachers opportunities to work collaboratively with school personnel and to help train a new group of pre-service teachers taking the introductory course. Each successive semester a new group of students will take the introductory course while experienced students enroll in the internship course and serve as site-based mentors for students in the introductory course. Current teachers in the pilot school receive a stipend for participating in the program and pre-service teachers enrolling in the second course also receive a stipend.

The program design is informed by the American Association of Colleges and Universities (AASC\&U) statement of high impact educational practices which include both community-based experiential learning accompanied by opportunities to reflect on that learning in the context of a course, and internships where students have the opportunity to work at a more involved level with greater participation in elementary classrooms.

With a modest grant providing support for a two course release from teaching responsibilities, a course was developed with the purpose of teaching both pre-service teachers and current teachers ways of teaching young students self-regulation skills; the goals of the course are to provide opportunities for pre-service teachers and current teachers to understand the importance of being able to manage and regulate one's impulses and emotional reactions, one's attention and focus, and one's ability to communicate and cooperate effectively and appropriately with peers and others. Additional goals include reading and discussing research-based evidence demonstrating the strong relationship between self-regulation and academic achievement; also, and perhaps most importantly, a major goal is provide numerous direct opportunities for both preservice teachers and current teachers to employ and infuse techniques to foster the development of selfregulation skills with young students during classroom instruction at the host school.

The host school is an elementary school located in a large, urban public school district; over $90 \%$ of students in the school district are eligible for free or reduced lunch. At the requests of faculty in the Department of Education at the local college situated in the school district, the superintendent of the school district selected the host school based on the low academic performance in the school and the willingness of the host school principal to participate in the study. A memorandum of understanding indicating a two year commitment for the project at the host school was agreed upon by the college and host school.

Prior to initiating the course in the host school, the instructor spend much time at the host school learning about the school's culture, about the academic vision for the school and it's student population, and about the teachers' goals, teaching philosophies, and classroom management styles. This effort was to ensure a respectful, collegial partnership among all parties of the college and the host school; by understanding the school's culture and vision, the college instructor can more easily direct pre-service teachers and course instruction toward working with teachers at the host school in a collaborative, professional manner, rather than creating a false perception of working simply to provide assistance for teachers and students at the host school. As a result, the course instructor, preservice teachers, and current teachers at the school are equal partners in conducting, evaluating, and reflecting on research directed toward teaching young children self-regulation skills. In addition, 
teachers should experience greater efficacy in their classroom management abilities.

\section{Conclusions}

The program will be assessed quantitatively and qualitatively. Results of the self-regulation /prosocial training for children will be tracked in two ways. First, student behavior referrals will be monitored with pre-, on-going, and post-training data; other data collected will include student grades, Core Curriculum assessments, student attendance, and other key measures as well as student self-evaluations and teacher and parent questionnaires. Pre-service teachers' knowledge base for teaching young students self-regulation skills through modeling, using hints and cues, and scaffolding learning activities to develop students' internal self-regulation for improvement in classroom management and student learning will be assessed at multiple points throughout the program using standard observational measures. Teachers' efficacy for teaching self-regulation skills with young children will be assessed at multiple points throughout the program using self-report instruments. Observational measures will be used to detect development in participants' facility with self-regulation program delivery. Interviews with school personnel will also be used to assess the program model's viability and sustainability from an organizational perspective.

Expected outcomes among the children participating in the program include the following. First, young students in the program will have significantly fewer behavior referrals indicating that classroom teachers are seeing improvement in selfregulation behaviors and students are actually implementing the positive behaviors being taught. Second, students participating in the program will experience improved academic achievement as evidenced by improved grades and other test scores; this measure is criterion-based. Third, students, classroom teachers, and parents of participating children will all report improved student behavior through questionnaires and student self-evaluations. Finally, children participating in the program will have improved school attendance/reduced absenteeism.

Other expected outcomes among pre-service teachers include increased knowledge and implementation in modeling, using hints and cues, and scaffolding activities to promote self-regulation skills in their students, increased skill in delivery of lessons within the program, and increased sense of efficacy for classroom management. At the request of department faculty, K-12 school administrators annually assess recent graduates' teaching, management, and assessment skills on detailed rubrics; information from rubrics identifies our graduates' skills and dispositions in classroom management and will also inform ways to improve the new course implementation and content. This assessment will track teacher retention rates for those teachers who were interns in the initiative as compared to state and national retention rates for all teachers.

The course and research project to teach young self-regulation skills was launched in the fall, 2013, academic year and will continue at the host school site each semester for a minimum of two years. Preservice teachers, along with current teachers, and the course instructor have an extended class at the host school one afternoon weekly at the end of the school day. Class activities include reading and discussing research of the effects of self-regulation behaviors on academic achievement, practicing modeling and providing hints and cues to promote self-regulation through role-playing and improvisation activities, and reflecting on strategies that are successful and why such strategies are successful, and also reflecting on unsuccessful strategies and reasons the strategies may have been unsuccessful. In addition to the class at the host school, pre-service teachers return to the school to devote three hours weekly to active participation in the host school classrooms. Pre-service teachers are to model, provide hints and cues, and to generally promote young students' awareness and development of self-regulation skills, with the goal toward students developing internalized self-regulation abilities.

Pre-service teachers' initial reactions to their observations and participation in classrooms at the host school early in the semester were consistent. Pre-service teachers found teachers to have authoritarian classroom management styles; preservice teachers reported that teachers addressed students in raised voices with occasionally seemingly harsh tones. Teachers frequently resorted to fairly rapid behavior referrals to the school administration following student infractions of classroom rules or expectations. Pre-service teachers described young students as responding initially to authoritarian classroom management and raised voices to correct behaviors, but students quickly resumed their behaviors, many of which were off-task behaviors such as not focusing or completing instructional tasks, arguing with peers, and random impulsive actions such as walking around the room during direct instruction, taking materials from others, and not keeping hands and feet to one's self. Later in the semester after teachers had attended several classes directed by the course instructor and with pre-service students, several teachers began to incorporate self-regulation modeling, hinting and cuing, and other practices in their instruction and management. Pre-service teachers reported students' on-task behaviors were 
improving and there were fewer infractions of classroom rules and expectations.

Initially at the beginning of the semester, preservice teachers unanimously reported their surprise at the frequency and degree of student misbehavior and off-task tendencies. After several weeks, preservice teachers described feelings of being overwhelmed and discouraged. However, as the semester progressed, pre-service teachers began to observe small changes in both the teachers and students at the host school. Classroom discipline seemed a bit less harsh and the students began to exhibit fewer off-task behaviors and acts of impulsiveness. Pre-service teachers ended the semester feeling encouraged; although progress towards developing self-regulation skills in young children was slow, pre-service teachers observed more displays of self-regulation skills among young children near the end of the semester. Pre-service teachers also observed teachers more frequently modeling, hinting, and cuing students to foster the development of self-regulation skills.

As the fall 2013 academic semester was the first semester of the collaborative research initiative, the mutual development of building trust and relationships among the host school, pre-service teachers, and the college instructor was essential. Establishing trust and developing relationships among all participants-host school teachers and administrators, elementary students, pre-service teachers, and the course instructor-evolves over time. Mid-way through the first semester of the initiative, the host school teachers began to readily participate in course discussions with pre-service teachers under the direction of the course instructor. In addition, as mutual trust was emerging, teachers and pre-service teachers participated in role-playing and other improvisational scenarios to explore in a safe environment options for managing student behavior and teaching self-regulation skills. Preservice teachers remained aware of the delicate balance between their role as mutual learners with host school teachers, and understood that the host classroom teachers were the "real" teachers with responsibility for their students; pre-service teachers at all times deferred to the host school teachers in areas of instruction, materials, and classroom management. This deference enhanced trust among teachers and pre-service teachers as clear boundaries were demonstrated.

In December at the conclusion of the fall semester, the first semester of the initiative, the host school principal reported to the course instructor that in classrooms with host teachers participating in the self-regulation class with pre-service teachers, no student misbehavior referrals had been sent to his office. The principal attributed this highly unusual occurrence directly to his teachers' participation in the self-regulation course. Teachers had learned to model and implement new strategies in classroom management to better support the development of student self-regulation. Teachers reported success with instituting more deliberate modeling, providing more hints and cues, and explicitly undergirding instruction with support and encouragement. In addition, teachers at the conclusion of the first semester of the initiative also reported that they had begun to feel somewhat less frustrated by student misbehavior and off-task behaviors; teachers stated that as they learned about the importance of selfregulation and learned ways of implementing strategies in their classrooms to develop selfregulation in their students, teachers began to practice self-regulation themselves and they modeled and taught self-regulation best practices with their students. As a result, both teachers and students experienced less frustration in the teaching and learning process.

As students learn to better regulate and express emotions in appropriate ways, to work cooperatively with others in small and large group settings, and to develop rehearsal strategies through direct teacher instruction and modeling, students experience fewer inappropriate emotional outbursts and exhibit more frequent pro-social behaviors. In addition, as teachers model and provide specific instruction in questions and procedures for deeper processing both text and instructional assignments, students practice and develop methods of attending to tasks for longer periods of time. As a result, both teachers and students experience less frustration and fewer inappropriate classroom management disruptions.

Assessing the impact of the first year of the initiative in the host school at the end of the academic year will include a review of program participants' grades and performance on school district examinations, behavioral referrals, and absentee rates as compared to these areas for students not involved in the study. In addition, questionnaires will be completed by participating teachers at the host school, students, and parents.

Other qualitative reflections on the impact of the initiative are in progress as the second semester of the program comes to a conclusion. After the host school principal and course instructor reviewed program impact with a lens toward ways of making the initiative even more impactful during the next academic year, several significant suggestions surfaced. First, teacher participation in the program next fall will be on a voluntary basis only rather than by the host school's principal requesting teacher participation. Second, participating teachers next fall will be required to complete weekly journal entries which will be shared with the course instructor. Purposes for journal entries include journaling for reflection on practices that were successful and those that were unsuccessful and include analysis of why certain behaviors and practices were 
successfully implemented and why other practices were unsuccessful. Such journal entries will initiate discussions during weekly class sessions with both pre-service teachers and host school teachers. The goal for journaling is to provide an opportunity for teachers and pre-service teachers to share and learn from their successes and failures in a safe, supportive environment. Toward the conclusion of the first semester of the initiative, trust was slowly developed. Host teachers realized that pre-service teachers and the course instructor were not at their school to provide quick, easy solutions for classroom management and student learning problems. The course instructor and pre-service teachers were working and learning with the teachers in a collaborative manner to improve teaching and learning for teachers, the course instructor, pre-service teachers, and school students. Now that such trust has been established, teachers' and pre-service teachers' journals will likely become powerful learning tools for all involved.

Another suggestion for improving program impact involves the course instructor observing in classrooms of teachers volunteering to participate in the initiative next fall. Again, trust had to be established with teachers before course instructor observations could be successfully implemented. Purposes of the observations include providing opportunities for the course instructor to participate in the instructional process as an assistant to the teacher; such participation will allow the course instructor to model ways of implementing selfregulation instruction in the curriculum; the course instructor will model ways of hinting and cuing students to practice self-regulation skills, ways of introducing rehearsal strategies and techniques for deeply processing and attending to text and assignments. Although all students will receive instruction designed to develop self-regulation behaviors, the course instructor will assist teachers in identifying those students needing more intensive, explicit modeling, hinting, and cuing for promoting self-regulation, with the ultimate goal being that all students will achieve internalized self-regulation.

Although self-regulation skills have been found to have a stronger link to academic achievement than IQ scores, there is little emphasis on direct, explicit instruction in ways to develop selfregulation skills. During the current educational climate's emphasis on various assessments to measure academic achievement coupled with emphasis on teacher accountability connected to such assessment scores, pre-service teachers and current teachers have not been taught the importance of self-regulation skills and often do not understand that such skills closely correlate to school achievement. In addition, pre-service teachers and current teachers have not been and are not currently trained in ways to teach self-regulation skills.
Teacher preparation providers must first review the scholarly literature, learn about and practice strategies for teaching self-regulation skills, and include instruction in ways of teaching selfregulation in teacher preparation programs. Instruction in preparing pre-service teachers to teach self-regulation skills in k-12 classrooms must be integral to all teacher education course content and imbedded throughout teacher preparation courses. Just as pre-service teachers practice best pedagogy in field sites during their coursework, preservice teachers must also include self-regulation skills development as a central component of elementary classroom instruction. The key to improving students' test scores likely does not lie in more test preparation practice sessions; teaching students self-regulation skills highly correlates with academic achievement and teacher preparation providers must prepare pre-service teachers to teach self-regulation skills and behaviors in today's classrooms.

\section{References}

[1] Bernard, M. E. "The relationship of young school children's social-emotional competence to their achievement and social-emotional well-being", Paper presented at the annual research conference of the Australian council for educational research, Adelaide, Australia, 2004

[2] Blair, C., \& Diamond, A. "Biological processes in prevention and intervention: The promotion of selfregulation as a means of preventing school failure", Development and Psychopathology, 2008, 899-911.

[3] Blum, R. W. \& Libbey, H. P. "School connectednessstrengthening health and education outcomes for teenagers", Journal of School Health, Blackwell, UK, 2004, 229-299.

[4] DuBois, D. L., Holloway, B. E., Valentine, J. C., \& Cooper, H. "Effectiveness of mentoring programs for youth: A meta-analytic review", American Journal of Community Psychology, Springer, Switzerland, 2002, 157198.

[6] Florez, I.R., "Developing young children's selfregulation through everyday experiences", Young Children, 2011.

[7] Galinsky, E. Mind in the Making: The Seven Essential Life Skills Every Child Needs. 2010, New York, HarperCollins.

[5] Durlak, J.A., Weissberg, R.P., Dymnicki, A.B., Taylor, R.D., Schellinger, K.B. "The impact of enhancing students' social and emotional learning: A meta-analysis of school-based universal interventions", Child Development, Wiley, New Jersey, 2011, 405-432. 
[8] Greenberg, M. T., Weissberg, R. P., O’Brien, M. U., Zins, J. E., et al. " Enhancing school-based prevention and youth development through coordinated social, emotional, and academic learning", American Psychologist, American Psychological Association, Washington, D.C., 2003, 466-474.

[9] Greenberg, M. T. (2006). "Promoting resilience in children and youth: Preventive interventions and their interface with neuroscience", Annals of the New York Academy of Sciences, New York Academy of Sciences, New York, 2006, 139-150.

[10] Jensen, E. Teaching with Poverty in Mind. Association for Supervision and Curriculum Development, 2009, Alexandria, VA.

[11] Kessler, R. The soul of education: Helping students find connection, compassion, and character at school. Association for Supervision and Curriculum Development, 2000, Alexandria, VA.

[12] Niesyn, M. “ Strategies for success: Evidence-based instructional practices for student with emotional and behavioral disorders", Preventing School Failure, 2009, Taylor and Francis Online, London, 227-232.

[13] Zimmerman, B. J. "Dimensions of academic selfregulation: A conceptual framework for education", SelfRegulation of Learning and Performance: Issues and Educational Applications, 1994, 3-24.

[14] Zins, J. E. \& Elias, M. J. "Social and emotional learning", Children's needs III: Development, prevention, and intervention, National Association of School Psychologists, 2006, Bethesda, MD.

[15] Pintrich, P.R. "The role of motivation in promoting and sustaining self-regulated learning", International Journal of Educational Research, 1999, 459-470. 